\title{
A genetic study of type 2 neurofibromatosis in the United Kingdom. I. Prevalence, mutation rate, fitness, and confirmation of maternal transmission effect on severity
}

D G R Evans, S M Huson, D Donnai, W Neary, V Blair, D Teare, V Newton, T Strachan, R Ramsden, R Harris

Department of Medical Genetics, St Mary's Hospital, Hathersage Road, Manchester M13 0JH. D G R Evans

T Strachan

D Donnai

$R$ Harris

\section{Department of} Medical Genetics, Churchill Hospital, Oxford.

S M Huson

Department of Audiology, University of Manchester, Manchester.

W Neary

V Newton

CRC Department of Cancer Genetics, Paterson Institute for Cancer Research, Christie Hospital, Manchester.

D G R Evans

CRC Paediatric and Familial Cancer Research Group, Christie Hospital, Manchester.

V Blair

D Teare

Department of Otolaryngology, Manchester Royal Infirmary,

Manchester.

R Ramsden

Correspondence to Dr Evans.

Received 11 April 1992. Revised version accepted 13 July 1992.

\begin{abstract}
A clinical and genetic study of type 2 neurofibromatosis (NF2) has been carried out in the United Kingdom. Virtually complete ascertainment of cases in the north-west of England was achieved and suggests a population incidence of 1 in 33000 to 40000 . In the UK as a whole, 150 cases have been identified and been used to study the clinical and genetic features of NF2. The autosomal dominant inheritance of NF2 was confirmed, $49 \%$ of cases were assessed as representing new mutations, and the mutation rate was estimated to be $6.5 \times 10^{-6}$. Evidence to support a maternal gene effect was found in that age at onset was $18 \cdot 17$ years in 36 maternally inherited cases and 24.5 in 20 paternally inherited cases $(p=0.027)$. The preponderance of maternally inherited cases was also significant $(p=0 \cdot 03)$. Data are presented which suggest that there are two types of NF2, one with later onset and bilateral vestibular schwannomas as the only usual feature, and the other with earlier onset and multiple other tumours. A considerable number of cases did not fall easily into one or other group and other factors such as maternal effect on severity and anticipation need to be considered.

( $(\mathcal{M}$ Med Genet 1992;29:841-6)
\end{abstract}

The first probable case of NF2 was reported by Wishart in $1820,{ }^{1}$ predating von Recklinghausen's paper on type 1 neurofibromatosis $(\mathrm{NF} 1)^{2}$ by over half a century. Following the description of von Recklinghausen's disease, however, many subsequent authors tended to classify patients with NF1 and NF2 as having the same disorder and failed to recognise the very different natural history of the two conditions. Although in 1930 Gardner and Frazier $^{3}$ reported a large kindred with bilateral vestibular schwannomas and suggested that the entity represented a separate, central form of von Recklinghausen neurofibromatosis, in their large study in 1956 Crowe et $a l^{4}$ did not distinguish between the two forms. Furthermore they reported that $5 \%$ of patients with von Recklinghausen neurofibromatosis had acoustic neuromas. In retrospect it is clear these patients had NF2.

The last two decades have seen an increasing awareness of the importance of distinguishing the different forms of neurofibromatosis. ${ }^{5-9}$ This period saw initial confusion in nomenclature with NF1 being referred to as peripheral or von Recklinghausen neurofibromatosis and NF2 as central or bilateral acoustic neurofibromatosis. In 1987 the mapping of the gene for NF1 to chromosome $17^{1011}$ and that of NF2 to chromosome $22^{1213}$ confirmed the clinical impression that the two diseases were distinct. The NIH Consensus Conference on neurofibromatosis in the same year gave clear guidelines on the nomenclature and diagnostic criteria of the two types (table 1).

In 1991 the NIH Consensus Conference on Acoustic Neuroma recommended another change to terminology. As the tumours are composed of schwann cells and typically involve the vestibular rather than the acoustic branch of the eighth cranial nerve, the term vestibular schwannoma rather than acoustic neuroma is suggested. We have therefore adopted this term.

As early as 1937 it was suggested NF2 could be divided into a severe and mild form. ${ }^{14}$ Recent studies have again drawn attention to this, ${ }^{15}$ recommending the severe form should be called Wishart, with early onset bilateral vestibular schwannomas and multiple other tumour types, and the mild form be called Gardner type, with usually only late onset bilateral vestibular schwannoma. It has also been suggested that the family reported by Lee and Abbott ${ }^{16}$ with multiple meningiomas as a major feature may be a third subtype.

Our interest in NF2 arose from genetic linkage studies and from the setting up of a neurofibromatosis register in Manchester in 1988 which led us to meet many subjects with

Table 1 Diagnostic criteria for NF2.

Bilateral vestibular schwannomas or family history of NF2 plus (1) unilateral acoustic or

(2) any two of: meningioma, glioma, neurofibroma, schwannoma, posterior subcapsular lenticular opacities 
NF2. The need for a clinical and genetic study of the disease was identified. There have been no previous population based studies on NF2 and no large studies in the British population. In this paper we report the genetic analysis of our study population and in the following paper guidelines for counselling and management are given. A detailed clinical description is reported elsewhere. ${ }^{17}$

\section{Patients and methods}

The study was carried out from May 1989 to October 1991. Patients were ascertained by contacting neurosurgeons, ENT surgeons, neurologists, paediatricians, dermatologists, and geneticists throughout the UK. Particular effort was made to reach full ascertainment for the north-west of England where case identification was augmented by extracting all cases of bilateral vestibular schwannoma and double primary vestibular schwannoma and meningioma from the North West Regional Cancer Registry occurring in the last 28 years. In addition to known cases of bilateral vestibular schwannoma, our ascertainment criteria included cases of unilateral vestibular schwannoma with spinal tumour or meningioma, multiple meningioma, and multiple spinal tumours.

Once a patient had been identified, permission was obtained to visit them and their first degree relatives at home. A standard questionnaire and clinical examination was completed for all family members; when possible a slit lamp examination of the lens was performed. After assessment a subject was classified as affected if their clinical features satisfied the NIH diagnostic criteria for NF2 (table 1).

\section{Results}

\section{PATIENT ASCERTAINMENT}

North West Regional study

After exclusion on the basis of insufficient criteria for the diagnosis of NF2, 19 living subjects were identified as having the condition in the North Western Regional Health Authority of England. A further nine cases who had died before the study were also identified. The diagnosis was confirmed from hospital records, scans, registration with the Regional Cancer Registry, and by personal examination; all but one of the living patients was examined by one of the authors. The total 28 cases came from 20 families. In five families the index case had died and no further affected family members were identified. A further two families were studied who had affected relatives outside the primary study area. No new cases were detected.

\section{UK study}

Although prevalence and incidence data needed to be obtained from a population where $100 \%$ ascertainment was possible, the 28 cases identified in the North West Region alone would have been too small for other analyses. We have received information on 150 cases from 91 families of whom 110 are alive; 97 patients have been examined by one of the authors and the majority of first degree relatives have also been seen. Audiological tests and cranial CT or MRI scans have been performed in many at risk relatives where possible to exclude subclinical disease.

DISEASE PREVALENCE

Prevalence was calculated from all affected persons in the population of the North West Regional Health Authority, which was 4016100 on prevalence day (1 June 1990). This gave a minimum prevalence of 19 / 4016100 , that is 0.47 per $100000\left(4 \cdot 7 / 10^{6}\right)$ of the population. The true prevalence is likely to be much higher as this figure includes only those who have a formal diagnosis of NF2.

Mean age at diagnosis in 110 subjects throughout the UK was 27.55 years and the severity of the condition results in early death in the majority of cases. Disease course from onset of symptoms averages 18.5 years, ${ }^{5}$ but in 22 cases in the UK the duration from diagnosis averaged only 8.09 years. Including the living cases, mean actuarial survival from diagnosis was 15 years. It would be logical to assume a greater degree of diagnostic delay among new mutations, especially as $13 / 56$ familial cases were diagnosed asymptomatically. Including the asymptomatic cases as zero delay from onset of symptoms, the mean delay was 4.91 years in familial cases compared to 6.28 years in sporadic cases.

In the North West Region there were 27 asymptomatic offspring of affected cases at $50 \%$ prior risk. A further case at $50 \%$ prior risk from a family outside the region but resident in Manchester was added. Analysis of the at risk offspring using age at onset data (table 2) predicted that 8.74 cases were likely to be heterozygotes. As approximately $50 \%$ of cases arise as new mutations, a similar number of asymptomatic sporadic heterozygotes would be expected. This gives a prevalence of 34.48 per 4003500 or 0.86 per 100000 .

\section{BIRTH INCIDENCE}

The diagnostic prevalence would underestimate birth incidence because of the late age at presentation and the early expected death. Death occurred at a mean age of 38.4 years in 37 cases, although mean actuarial survival was

Table 2 Cumulative incidence and mortality in NF2.

\begin{tabular}{ccccc}
\hline Age & $\begin{array}{c}\text { No } \\
\text { affected }\end{array}$ & $\begin{array}{c}\text { Cumulative } \\
\text { incidence }\end{array}$ & $\begin{array}{c}\text { No of } \\
\text { deaths }\end{array}$ & $\begin{array}{c}\text { Cumulative } \\
\text { mortality }\end{array}$ \\
\hline $0-5$ & 6 & 0.054 & 0 & 0 \\
$6-10$ & 5 & $0 \cdot 10$ & 0 & 0 \\
$11-15$ & 19 & 0.273 & 0 & 0.008 \\
$16-20$ & 27 & 0.518 & 4 & 0.031 \\
$21-25$ & 18 & 0.682 & 3 & 0.057 \\
$26-30$ & 17 & 0.836 & 9 & $0 \cdot 127$ \\
$31-35$ & 5 & 0.882 & 8 & $0 \cdot 208$ \\
$36-40$ & 5 & 0.927 & 5 & $0 \cdot 318$ \\
$41-45$ & 6 & 0.982 & 1 & 0.357 \\
$46-50$ & 1 & 0.99 & 2 & $0 \cdot 404$ \\
$51-55$ & 1 & 1.0 & 1 & 0.434 \\
$56-60$ & 0 & 1.0 & 1 & 0.483 \\
$61-65$ & 0 & 1.0 & 3 & 0.571 \\
$66-70$ & 0 & 1.0 & 1 & 1.0 \\
Total & 110 & & 38 & \\
\hline
\end{tabular}


63 years including the living cases (table 2). Therefore other assessments of disease incidence had to be used. In the decade 1980 to 1989,17 cases of NF2 were diagnosed in the North West Region. This represents an annual incidence of 1 case per 2355000 people. The median birth year for those being diagnosed in that decade was 1958 (range 1926 to 1976) and the average age at diagnosis of NF2 was 27.55 years. Using the annual birth rates for the region for the decade around 1958 (1953 to 1962), as suggested by both these pieces of information, this represented a birth incidence of 1 per 40562 (17/689568 live births).

Using age at diagnosis and current regional statistics for those alive in the five year age groups, the cumulative incidence can be calculated from the annual incidence rate for each age group. The cumulative incidence is a good approximation to the lifetime risk of developing NF2 in the absence of competing mortality. The cumulative incidence provides an estimate of birth incidence as long as the age specific incidence rate is constant over time. ${ }^{18}$ By this method the birth incidence was estimated to be 1 in 33000 . Both these calculations assume $100 \%$ penetrance and the former that there is no loss of NF2 cases from birth before diagnosis.

\section{PEDIGREE ANALYSIS}

Although we have received information on 150 cases from 91 families of whom 110 are alive, information was considered complete in only 68 pedigrees containing 122 cases; 110 of these cases had full details of age of onset and disease course.

The pedigrees were consistent with the expected autosomal dominant inheritance of NF2. There were many examples of male to male transmission and there was no statistically significant difference in the number of each sex affected when NF2 was inherited from a known case (30/57 were male). As the mean age at diagnosis was 27.55 years, the number of definite NF2 cases was less than the expected $50 \%$ figure $(57 / 181)$. However, when children under the age of 10 are excluded (diagnosis occurred in only $1 / 110$ cases in this series), the figure is less discrepant (57/146). There was one four generation family and six three generation families.

Of these 110 cases, 36 were considered to have inherited the gene for NF2 from their mother, 20 from their father, and 54 were considered to have arisen as new mutations. The difference in number of cases inheriting the gene from each parent was significant $(p=0.03)$. A case was considered to have arisen through new mutation only after an extensive family history was taken for features of NF2 in relatives. Where possible the parents and sibs were also examined and the outcome in 49/54 families studied by the authors is shown in table 3 .

There appeared to be a marked degree of heterogeneity within NF2. Our pedigrees confirmed previous reports of marked interfamilial variation of disease; presentations within a family were relatively uniform although with some variation in age of presentation. There were two broad types of families.

(1) Mild: characterised by relatively late onset ( $>15$ years, but usually $>25$ years) of bilateral vestibular schwannoma, with only minimal skin manifestations and occasional other CNS tumours (no more than one spinal tumour or meningioma). Progression of tumours is often very slow.

(2) Severe: with early onset ( $<30$ years, but usually $<25$ years) and meningiomas and spinal tumours in frequent numbers (at least two of one type and usually multiple) in addition to bilateral vestibular schwannomas, which are the presenting feature in only $50 \%$ of cases. Disease course is often rapid causing severe handicap or death before reproductive age. The peripheral features are more pronounced in the severe cases.

Examples of three families with the mild type and two with the severe type, with both maternal and paternal inheritance, are presented in table 4. There were, however, a large number of cases (12/120) which did not fit exactly into this classification, for example, two cases with multiple meningiomas and a unilateral vestibular schwannoma presenting at 30 and 43 years respectively. A 28 year old woman whose father had typical type $2 a$ disease, with onset aged 28 years, presented aged 6 years with seizures owing to a meningioma and has since developed a spinal tumour. Another woman with a family history of type 2a disease presented aged 8 years with a vestibular schwannoma and now has a meningioma at 21 years. In contrast to typical type $2 b$ cases these two are extremely well and disease course and tumour growth has been slow, as in another case who at the age of 11 years reverted from the family type $2 \mathrm{a}$ disease course by presenting with a spinal tumour. No familial case has reverted from type $2 b$ to type $2 a$;

Table 3 Details of parents, sibs, and offspring for 49 cases of NF2 without a family history.

\begin{tabular}{|c|c|c|c|c|c|c|c|c|}
\hline \multirow[b]{3}{*}{ Parents } & \multirow{3}{*}{$\begin{array}{l}\text { No of } \\
\text { cases }\end{array}$} & \multicolumn{3}{|c|}{ Sib data } & \multicolumn{4}{|c|}{ Offspring data } \\
\hline & & \multicolumn{2}{|c|}{ Living } & \multirow[t]{2}{*}{ Dead } & \multirow[t]{2}{*}{ Aff } & \multirow[t]{2}{*}{ Unaff } & \multirow[t]{2}{*}{ Equiv } & \multirow[t]{2}{*}{$\mathrm{NE} / \mathrm{N}$} \\
\hline & & Examined & $\mathrm{NE} / \mathrm{N}$ & & & & & \\
\hline $\begin{array}{l}\text { Both examined } \\
\text { One examined + one dead } \\
\text { Divorced, one examined } \\
\text { Both dead } \\
\text { One dead, other unwilling } \\
\text { One only examined } \\
\text { Neither } \\
\text { Total } \\
\text { Inadequate detail: adoption } 1 \text { case }\end{array}$ & $\begin{array}{r}15 \\
4 \\
2 \\
8 \\
7 \\
3 \\
9 \\
48\end{array}$ & $\begin{array}{r}8 \\
2 \\
4 \\
0 \\
6 \\
6 \\
1 \\
27\end{array}$ & $\begin{array}{r}20 \\
5 \\
0 \\
15 \\
16 \\
2 \\
18 \\
76\end{array}$ & $\begin{array}{l}0 \\
0 \\
0 \\
3 \\
1 \\
0 \\
0 \\
4\end{array}$ & $\begin{array}{l}0 \\
0 \\
0 \\
4 \\
2 \\
0 \\
2 \\
8\end{array}$ & $\begin{array}{r}5 \\
1 \\
0 \\
5 \\
12 \\
2 \\
5 \\
30\end{array}$ & $\begin{array}{l}1 \\
1 \\
0 \\
0 \\
1 \\
0 \\
1 \\
4\end{array}$ & $\begin{array}{r}4 \\
0 \\
0 \\
3 \\
2 \\
0 \\
4 \\
13\end{array}$ \\
\hline
\end{tabular}

NE/N - not examined, but reported normal. 
Table 4 Examples of families with severe and mild types of NF2.

\begin{tabular}{|c|c|c|c|c|c|c|}
\hline \multirow[b]{2}{*}{ Subject } & \multirow[b]{2}{*}{ Relation } & \multicolumn{3}{|c|}{ Age (y) } & \multirow[b]{2}{*}{ CNS tumours } & \multirow[b]{2}{*}{ Skin tumours } \\
\hline & & Onset & Current & Death & & \\
\hline $\begin{array}{l}\text { Mild type } 1 \\
\text { Family } 1 \\
\text { A (male) } \\
\text { B } \\
\text { C }\end{array}$ & $\begin{array}{l}\text { rdner type) } \\
\text { Index } \\
\text { Son of A } \\
\text { Daughter of A }\end{array}$ & $\begin{array}{l}40 \\
39 \\
43\end{array}$ & $\begin{array}{l}67 \\
44 \\
44\end{array}$ & & $\begin{array}{l}\text { BVS } \\
\text { BVS, } 1 \mathrm{M} \\
\text { BVS }\end{array}$ & $\begin{array}{l}0 \\
0 \\
0\end{array}$ \\
\hline $\begin{array}{l}\text { Family 2 } \\
\text { A (female) } \\
\text { B } \\
\text { C } \\
\text { D }\end{array}$ & $\begin{array}{l}\text { Index } \\
\text { Daughter of A } \\
\text { Daughter of } B \\
\text { Daughter of } B\end{array}$ & $\begin{array}{l}32 \\
29 \\
24 \\
28\end{array}$ & $\begin{array}{l}60 \\
35 \\
29\end{array}$ & 34 & $\begin{array}{l}\text { BVS } \\
\text { BVS, 1M } \\
\text { BVS, 1M } \\
\text { BVS }\end{array}$ & $\begin{array}{l}\text { NK } \\
1 \\
0 \\
0\end{array}$ \\
\hline $\begin{array}{l}\text { Family } 3 \\
\text { A (male) } \\
\text { B } \\
\text { C } \\
\text { D }\end{array}$ & $\begin{array}{l}\text { Index } \\
\text { Son of A } \\
\text { Son of A } \\
\text { Son of A }\end{array}$ & $\begin{array}{l}59 \\
43 \\
45 \\
22\end{array}$ & $\begin{array}{l}45 \\
47 \\
42\end{array}$ & 63 & $\begin{array}{l}\text { BVS } \\
\text { BVS } \\
\text { BVS } \\
\text { BVS }\end{array}$ & $\begin{array}{l}\text { NK } \\
\text { NK } \\
0 \\
0\end{array}$ \\
\hline $\begin{array}{l}\text { Severe type } \\
\text { Family } 1 \\
\text { A (female) } \\
\text { B } \\
\text { C } \\
\text { D } \\
\text { E }\end{array}$ & $\begin{array}{l}\text { ishart type) } \\
\text { Index } \\
\text { Daughter of A } \\
\text { Daughter of A } \\
\text { Daughter of B } \\
\text { Son of C }\end{array}$ & $\begin{array}{r}20 \\
20 \\
6 \\
18 \\
11\end{array}$ & $\begin{array}{l}42 \\
39 \\
22 \\
12\end{array}$ & 27 & $\begin{array}{l}\text { BVS, 1M } \\
\text { BVS, 6M, SP } \\
\text { BVS, SP } \\
\text { BVS, 1M, 1G } \\
\text { UVS }\end{array}$ & $\begin{array}{l}\text { NK } \\
6 \\
5 \\
1 \\
2\end{array}$ \\
\hline $\begin{array}{l}\text { Family } 2 \\
\text { A (male) } \\
\text { B } \\
\text { C }\end{array}$ & $\begin{array}{l}\text { Index } \\
\text { Daughter of A } \\
\text { Daughter of A }\end{array}$ & $\begin{array}{l}26 \\
14 \\
21\end{array}$ & $\begin{array}{l}31 \\
26\end{array}$ & 26 & $\begin{array}{l}6 \mathrm{M} \\
\text { BVS, 1M } \\
\text { BVS, SP }\end{array}$ & $\begin{array}{l}\text { NK } \\
3 \\
1\end{array}$ \\
\hline
\end{tabular}

BVS = bilateral vestibular schwannoma, $M=$ meningioma, $S P=$ spinal tumour, $G=$ glioma.

although some offspring of type $2 \mathrm{~b}$ cases presented with a vestibular schwannoma, they inevitably went on to develop multiple other tumours. Only 4/60 type 2a cases presented with symptoms not resulting from a vestibular schwannoma compared to $23 / 60$ type $2 b$ cases who presented with symptoms resulting from a spinal tumour or meningioma. We found no evidence for any other types of NF2 or cases with classical features of NF1 and NF2.

ESTIMATION OF FITNESS

This was performed by comparing number of offspring of affected cases per 100 reproductive years with their unaffected sibs. The relative fitness was 0.93 overall. Affected cases had 158 offspring in 1958 reproductive years. Unaffected cases had 309 offspring in 3561 years. 45.

Reproductive years were defined as age 16 to

Fitness $=\frac{158 / 1958 \times 100}{309 / 3561 \times 100}=0.93$.

Ratio of completed family sizes was $2 \cdot 106: 2 \cdot 1831$.

The level of 0.93 did not adequately allow for loss of life occurring before reproductive age was attained or for limitation of family size by the unaffected cases. Completed family size allows for all affected and unaffected cases dying without children. The methods of Tanaka ${ }^{1920}$ were therefore used. By this method fitness was:

Fitness $=0.46-0.51$

Relative fitness in males $=0 \cdot 27$.

Relative fitness in females $=0 \cdot 76$.

\section{MUTATION RATE}

Direct method

Mutation rate by the direct method ${ }^{21}$ used the number of cases from the decade studied caused by new mutation; $9 / 17$ cases where the family had been studied represent new mutations. Seven cases were clearly familial and a further case had not had a family study. Therefore:

Mutation rate $=$

$$
9 / 2 \times 689568=(6 \cdot 5 \pm 2 \cdot 16) \times 10^{-6} .
$$

\section{Indirect method}

As we have calculated the birth incidence as 1 in 33 to 40562 and it is unlikely that a case will not eventually present with diagnostic features even as a new mutation, the indirect method can also be used. ${ }^{18}$

$$
\begin{aligned}
& \text { Mutation rate }= \\
& \text { incidence } \times(1-\text { fitness }) / 2=(1 \cdot 0-8 \cdot 2) \times 10^{-6} .
\end{aligned}
$$

PARENTAL AGE AND MUTATION

The birth order data on 44 new mutations are presented in table 5. Information was considered inadequate in the remaining 10 families. No significant birth order effect was found using the method of Haldane and Smith ${ }^{22}$ to analyse the data $(p=0.75)$. For 39 of the new mutations the age of both parents at their birth was known. The mean paternal age was $31 \cdot 18$ and mean maternal age was $27 \cdot 31$. This compares with expected ages of $30 \cdot 19$ and $27 \cdot 15$

Table 5 Birth order in 44 new mutations.

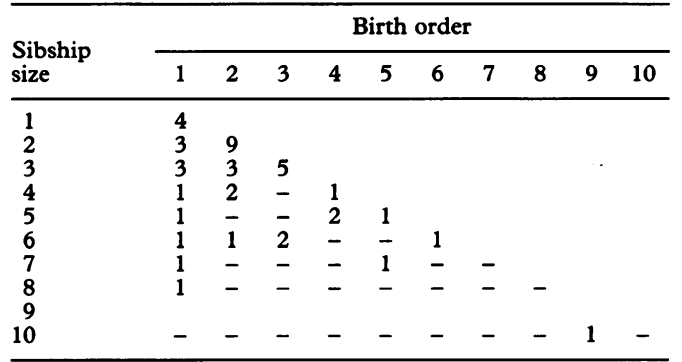


years respectively when corrected for year of birth and taken from the Registrar General's population data. This difference is not significant.

PARENTAL EFFECT ON SEVERITY

The mean age at first symptom or diagnosis in 36 maternally inherited cases was $18 \cdot 17$ years (SD 8.84, SE 1.47, median 18). The mean age in paternally inherited cases was 24.5 years (SD 11.83, SE 2.65, median 22.5). The difference in average age of onset of 6.33 years was significant $(p=0.026)$. There was a general impression of a worse clinical course in maternally inherited cases and average age at death in six cases was 24.33 years, compared to 39.33 in three paternally inherited cases.

\section{Discussion}

A population based study of NF2 in the UK has identified 150 cases from 91 families. Segregation analysis confirmed the expected autosomal dominant single gene mode of transmission. There is almost complete penetrance by the age of 60 , although a broader definition than the NIH consensus criteria is required..$^{23}$ There were no cases of affected sibs born to apparently normal parents and no cases of proven non-penetrance within families. One 67 year old obligate carrier resident in New Zealand has had two affected daughters, and although he has required a hearing aid for some years has only recently had investigations to confirm his diagnosis. The only case not to be confirmed was a 36 year old obligate carrier who inherited the gene from her mother. She has had two affected children, but died of a myocardial infarction at the age of 36 with no suspicious features of NF2. One case of probable non-penetrance was reported by Young et $a l,{ }^{24}$ although she died in her early fifties without specific investigation. Kanter et $a \bar{l}$ also confirmed autosomal dominant inheritance in nine kindreds they studied personally and 15 published ones. A further two possible cases of non-penetrance were alluded to, but no information on age was given. Penetrance is likely therefore to be close to $100 \%$ by 60 , especially if modern diagnostic imaging (MRI with gadolinium enhancement) is used to confirm the diagnosis.

Although we have drawn attention to the heterogeneity in NF2 the evidence for two subtypes as described recently is still not overwhelming. ${ }^{15}$ Some cases are very difficult to classify if they have a single meningioma in addition to vestibular schwannomas, while other cases with late onset may have multiple meningiomas. Classifying the condition purely on age at onset is clearly artificial, especially in view of the maternal gene effect. In view of the recent molecular analysis in myotonic dystrophy, ${ }^{25}$ another mechanism which has to be considered to explain variable age at onset is anticipation. As so few multigeneration families were identified in the present study, this issue is difficult to address. It is of interest that in the initial report of the largest NF2 family reported to date, Gardner and Frazier ${ }^{3}$ drew attention to the decrease in age at death in successive generations $(72,64,42$, and 28 years in generations I to IV respectively). The cloning of the NF2 gene will mean that the pathogenesis of these clinical observations can be addressed at the molecular level. At a practical level the very different disease course and manifestations in some families remains very constant and has clinical implications as discussed elsewhere. ${ }^{26}$

There have been no previous population based studies of NF2. Previous estimates of prevalence are likely to have been underestimates. ${ }^{5}$ The only estimate of incidence 9 appears to have been accurate, although no statement is made as to how it was calculated. It is likely that a birth incidence of around 1 in 30 to 50000 holds true for most of the western world. There is little information on nonCaucasian populations, although there were three cases from two families from the Indian subcontinent in this series. The major difficulty in assessing birth incidence is the late age at diagnosis, 27.55 years in this study, and early age at death. A diagnostic prevalence in this study of 1 in 210000 would have seriously underestimated both incidence and mutation rate if used in the direct method of calculation. We have assumed $100 \%$ eventual penetrance in our study, so the only possible upward bias is if more cases were ascertained in the decade studied owing to heightened awareness and better diagnostic imaging.

The mutation rate is certainly higher than previously thought, ${ }^{5}$ although there has been no previous attempt to calculate it. Several reports have indicated that half their cases were sporadic: $11 / 15,{ }^{27} 22 / 38,{ }^{28}, 6 / 12 .{ }^{29}$ When unbiased studies are used, where familial cases are not specifically sought, there appears to be good support for $50 \%$ of cases being the result of new mutation. Although non-paternity and non-penetrance could slightly reduce this figure, a high mutation rate is necessary to maintain incidence. The direct method was considered to be accurate. The indirect method relies heavily on the calculation of genetic fitness. Reproductive fitness is unsuitable for this measurement and the method of Tanaka is not accurate enough as NF2 is a rare disease which is not fully penetrant in early life.

In contrast to the huge families reported from the USA, ${ }^{35}$ there were only two families with more than five affected cases. The first with nine known cases has been reported before. ${ }^{7}$ The second has eight cases in three generations, although three cases are outside the UK. There was no strong support for advanced paternal age as a mechanism to support the relatively high figure for mutation rate. Further studies are certainly needed as there was some suggestion of an effect from the increase in expected age of the fathers of just under a year and the skew towards the later pregnancies in the birth order data. The figure for mutation rate of $6.5 \times 10^{-6}$ is less than that in NF1 (3.1 to $\left.10.4 \times 10^{-5}\right),{ }^{30}$ but greater than in von Hippel-Lindau disease $\left(4.4 \times 10^{-6}\right) .^{31}$

There have been no previous studies that have looked at genetic fitness. We were sur- 
prised by the relatively normal level of fitness in NF2 calculated by comparing unaffected sibs; however, fitness is only measurable in people old enough to be diagnosed. Early age at onset in several cases clearly reduces fitness but as these cases remain young their data could not influence the calculations. Sibs may also reduce their families voluntarily because of the known genetic mechanism. The methods of Tanaka ${ }^{192}$ rely on high levels of certainty of the diagnosis; this is approached but certainly not complete at 15 years of age. However, the younger cases are accounted for and it is therefore felt to be more accurate. The reduced fitness in males as compared to females could well be partially explained by the later expected age at marriage and first birth in males.

A maternal gene effect was first suggested by Kanter $e t a l \bar{l}$ who found a significant difference in their age of onset between maternally and paternally inherited cases. This study which is larger and contains more personally examined cases confirms the results with very similar figures. Age at onset in our maternal cases was 18.17 years compared to 18.3 years in the study of Kanter $e t a l^{5}$ and in paternal cases 24.5 as opposed to $24 \cdot 1$. This along with the earlier age at death in maternal cases suggests that gene modification by imprinting could be involved in NF2.32 The previous study also found a non-significant difference in the number of cases inheriting the gene from each parent; $25 / 38$ cases were maternally inherited compared to $36 / 56$ in our study. When combined, this too reaches significance $(p=0.004)$. The effect could be explained to some extent by reduced fitness in males and by some cases of non-paternity among the sporadic cases. However, it is possible that if an imprinting effect is present, the later onset and possibly non-penetrant cases of paternal origin would be missed, although we could find no evidence of non-penetrance in our study.

In conclusion our study has shown NF2 to have a birth incidence of 1 in 35000 and that $50 \%$ of cases in a given series are the result of new mutation, with a mutation rate of $6.5 \times 10^{-6}$. The study has confirmed wide interfamilial variation in presentation of NF2, although definition of severe and mild subtypes on clinical criteria alone is not possible in many cases because of overlapping features, the situation being further complicated by the maternal effect on disease severity. The cloning of the NF2 gene is imminent and phenotype-genotype studies in our large study population will allow us to address disease heterogeneity at a molecular level. There is no evidence of locus heterogeneity from published ${ }^{33}$ and unpublished ( $\mathrm{T}$ Strachan, personal communication) linkage studies. There is no clear evidence of a paternal age effect on mutation, but a definite maternal effect on severity. The mechanism of mutation and the maternal effect on disease severity will hopefully be eludicated after the cloning of the NF2 gene.

We are grateful for the enormous help supplied by clinicians throughout the UK who have given details of patients. We would particularly like to thank Mr T T King for supplying 19 cases and the Neurosurgical Unit at the Manchester Royal Infirmary for their help in ensuring good ascertainment.

1 Wishart JH. Case of tumours in the skull, dura mater, and brain. Edinburgh Med Surg f 1820;18:393-7.

2 Von Recklinghausen F. Ueber die multiplen fioroma der haut und ihre beziehung zu den multiplen neuromen. Berlin: A Hirschwald, 1882 .

3 Gardner WJ, Frazier $\mathrm{CH}$. Bilateral acoustic neurofibromas: a clinical study and field survey of a family of five generations with bilateral deafness in thirty eight memgenerations with bilateral deafness in thirty ei
bers. Arch Neurol Psychiatr 1930;23:266-302.

4 Crowe FW, Schull WJ, Neal JV. A clinical, pathological and genetic study of multiple neurofibromatosis. Springfield, Illinois: Charles C Thomas, 1956.

5 Kanter WR, Eldridge R, Fabricant R, Allen JC, Koerber T. Central neurofibromatosis with bilateral acoustic neuroma: genetic, clinical and biochemical distinctions from peripheral neurofibromatosis. Neurology 1980;30:851-9.

6 Riccardi VM. Von Recklinghausen neurofibromatosis. $N$ Engl f Med 1981;305:1617-27.

7 Huson SM, Thrush DC. Central neurofibromatosis. $Q \mathcal{F}$ Med 1985;55:213-24.

8 Huson SM, Harper PS, Compston DAS. Von Recklinghausen neurofibromatosis: a clinical and population based study in southeast Wales. Brain 1988;111:1355-81.

9 National Institutes of Health Consensus Development Conference Statement on Neurofibromatosis. Neurofibromatosis Res Newsl 1987;3:3-6.

10 Seizinger BR, Rouleau GA, Ozelius LG, et al. Genetic linkage of von Recklinghausen neurofibromatosis to the linkage of von Recklinghausen neurofibromatosis to the
nerve growth factor receptor gene. Cell 1987;49:589-94.

11 Barker D, Wright E, Nguyen K, et al. Gene for von Recklinghausen neurofibromatosis is in the pericentro-

12 Seizinger BR, Martuza RL, Gusella JF. Loss of genes on chromosome 22 in tumorigenesis of human acoustic neuroma. Nature 1986;322:644-7.

13 Rouleau G, Seizinger BR, Ozelius LG, et al. Genetic linkage analysis of bilateral acoustic neurofibromatosis to a DNA marker on chromosome 22. Nature 1987;329:246-8.

14 Worster-Drought C, Dickson WEC, McMenemey WH. Multiple meningeal and perineural tumours with analagous changes in the glia and ependyma (neurofibroblastomatosis). Brain 1937;60:88-117.

15 Eldridge R, Parry DM, Kaiser-Kupfer MI. Neurofibromatosis 2: clinical heterogeneity and natural history in 39 individuals in 9 families and 16 sporadic cases. Am $\mathrm{f} \mathrm{Hum}$ Genet 1991;49:32.

16 Lee DK, Abbott ML. Familial central nervous system neoplasia. Arch Neurol 1969;20:154-60.

17 Evans DGR, Huson S, Donnai D, et al. A clinical study of type 2 neurofibromatosis. $Q \mathcal{F}$ Med (in press).

18 Breslow NE, Day NE. Statistical methods in cancer research. Volume 1. The analysis of case control studies. Lyon: IARC, 1980

19 Tanaka K. A new simplified method for estimating relative fitness in man. Finrui Idengaku Zasshi 1974;19:195-202.

20 Tanaka $\mathrm{K}$. Estimation of relative fitness in human abnormalities with sex difference in selection intensity: a new simplified method. Finrui Idengaku Zasshi 1975;20:183-6.

21 Emery AEH. Methodology in medical genetics. Edinburgh: Churchill Livingstone, 1986.

22 Haldane JBS, Smith CAB. A simple exact test for birth order effect. Ann Eugen 1947:14:117-24.

23 Evans DGR, Huson S, Donnai D, et al. A genetic study of type 2 neurofibromatosis. II. Guidelines for genetic countype 2 neurofibromatosis. II. Guidelines
selling. $\Im$ Med Genet 1992;29:847-52.

24 Young PF, Eldridge R, Nager GT, Deland FH, McNew J. Hereditary bilateral acoustic neuroma (central neurofiHereditary bilateral acoustic neuroma (cen
bromatosis). Birth Defects 1971;7:73-86.

25 Harley HG, Brook DJ, Rundle SA, et al. Expansion of an unstable DNA region and phenotypic variation in myotonic dystrophy. Nature 1992;355:545-51.

26 Evans DGR, Ramsden R, Harris R, Lye R, Huson SM, King TT. Type 2 neurofibromatosis: the need for supraregional care? $\mathcal{f}$ Laryngol Otol (in press)

27 Martuza RL, Ojemann RG. Bilateral acoustic neuromas clinical aspects, pathogenesis and treatment. Neurosurgery 1982;10:1-12.

28 Glasscock ME, McKennan KX, Levine SC. Acoustic neuroma surgery: the results of hearing conservation surgery. Laryngoscope 1987;97:785-9.

29 Hitselberger WE, Hughes RL. Bilateral acoustic tumours and neurofibromatosis. Arch Otolaryngol 1968;88:700-11.

30 Huson SM, Compston DAS, Clark P, Harper PS. A genetic study of von Recklinghausen neurofibromatosis in south study of von Recklinghausen neurofibromatosis in south east Wales. I. Prevalence, fitness, mutation rate, and 1989;26:704-11.

31 Maher ER, Iselius L, Yates JRW, et al. Von Hippel-Lindau disease: a genetic study. $\mathcal{f}$ Med Genet 1991;28:443-7.

32 disease: a genetic study. $\mathcal{F}$ Med Genet $1991 ; 28: 443-7$. human disease. Am $\mathcal{f}$ Hum Genet 1990;46:857-73.

33 Rouleau GA, Narod SA, Faucher JA, Haines JA, Gusella JF. There is no non-allelic genetic heterogeneity in neurofibromatosis type 2. Am f Hum Genet 1991; 49(suppl):357. 